\title{
Can models of presence-absence be used to scale abundance? Two case studies considering extremes in life history
}

\author{
Scott E. Nielsen, Chris J. Johnson, Douglas C. Heard and Mark S. Boyce
}

\begin{abstract}
Nielsen, S. E., Johnson, C. J., Heard, D. C. and Boyce, M. S. 2005. Can models of presence-absence be used to scale abundance? Two case studies considering extremes in life history. - Ecography 28: 197-208.
\end{abstract}

\begin{abstract}
Understanding patterns of species occurrence and abundance is a central theme of ecology, natural resource management, and conservation. Although occurrence models have been widely used for describing species distribution, particularly for rare species, abundance models are less common, despite greater information for conservation and management. Because presence-absence data are easier and less expensive to collect, predictions of abundance from patterns of occurrence could prove useful. We examined the relationship between occurrence and abundance for two species with very different life histories: bracken fern Pteridium aquilinum and moose Alces alces. We predicted that if occurrence and abundance were functionally related we should observe: 1) correlation between predicted probability of occurrence and observed abundance; 2 ) similar environmental covariates and estimated coefficients for occurrence models developed separately for low-density, high-density, and global data sites; and 3) parallel coefficients for the occurrence and abundance components of zero-inflated count models. Probability of occurrence was not correlated with abundance-when-present for bracken fern, while evidence for a relationship for moose was apparent at densities of animals below 7 individuals per cutblock. Coefficients for models at different levels of density did not vary significantly. However, once occurrence was accounted for, measured environmental data appeared less important in describing abundance. For bracken, covariates of zero-inflated count models differed in their expression of occurrence and abundance. Differences were less extreme for moose; however, results from the two-process models suggest that distribution and abundance may be a function of different processes. Environmental factors influencing abundance may differ from those limiting distribution. Life history, scale, site history, and sociocompetitive processes further help shape patterns of abundance. Two-stage modeling provides a powerful tool for describing animal and plant distribution where the processes of occurrence and abundance are influenced by different factors.
\end{abstract}

S.E.Nielsen (scottn@ualberta.ca),C.J. Johnson and M. S. Boyce, Dept of Biological Sciences, Univ. of Alberta, Edmonton, AB, Canada T6G 2E9. - D. C. Heard, British Columbia Ministry of Water, Land and Air Protection, 4051-18th Ave., Prince George, $B C$, Canada V2N $1 B 3$ (present address of C. J. J.: Ecosystem Sciences and Management Program, Univ. of Northern British Columbia, 3333 Univ. Way, Prince George, BC, Canada V2N 4Z9).

Understanding patterns and mechanisms of species occurrence and abundance is a central theme of ecology and biogeography. The field of conservation biology, in particular, has a rich history of use with applications ranging from the description and prediction of sedentary and mobile organisms (Austin et al. 1990), to the management and conservation of rare species (Mladenoff et al. 1995, Johnson et al. 2004). The adoption of occurrence models for conservation and management reflects the accessibility of presence-absence and

Accepted 25 October 2004 
use-availability data, prevalence of methods, and the accumulation of spatial digital information now available in geographic information systems (GIS). Recently, researchers have demonstrated the utility of count models, such as Poisson and negative binomial, for predicting plant and animal density and conducting population estimates (Pearce and Ferrier 2001, Boyce et al. 2001, Barry and Welsh 2002). Relative to occurrence modelling, such approaches typically provide a greater understanding and inference for conservation and management. Most ecological data, however, consists of a large number of absences (zeros) leading to problems of overdispersion (McCullagh and Nelder 1989). As a solution, researchers have modeled count data as a two-step process: first fitting a model to account for occurrence and a second model to represent abundance once occurrence is predicted (Welsh et al. 1996, Guisan et al. 1998). More recently, Barry and Welsh (2002) suggest use of a zero-inflated count model. Although the above techniques deal with overdispersion, count data are difficult and expensive to collect. Given that we most often collect data describing the presence or absence of plants and animals, conservation and management would benefit if abundance and associated ecological relationships could be inferred from models of occurrence.

At the scale of mapped individuals, abundance can be predicted using aggregation or "clumping" parameters (Gaston and Lawton 1990, He and Gaston 2000, He et al. 2002). These approaches are dependent on precise maps of animal or plant distribution and do not relate abundance to environmental conditions. Thus, application is limited by data constraints and results provide only limited inference to conservation and management.

An alternative method is the explicit use of environmental variables to index abundance from predictions of occurrence models. Environment-based modelling has wide application to natural resources management and conservation problems. One can explore, for example, the impacts of land use change or natural disturbance on species occupancy and abundance (McDonald and McDonald 2002). Boyce and McDonald (1999) suggest the use of a resource selection function to develop a total population estimate for animals that vary in density relative to habitats with differing probabilities of occurrence. Although the technique has shown promise (Boyce and Waller 2003), little has been done to test the generality of the occurrence-abundance relationship (but, see Pearce and Ferrier 2001). Given the widespread use of environmental occurrence models and the potential for predicting abundance, perhaps even at large sampling scales, it is important to test potential relationships among occurrence and abundance, examining where and when such relationships may hold true.
Previous research has reported inconsistencies between predictions of occurrence and abundance, but provided little insight into the mechanisms that affect that relationship (Pearce and Ferrier 2001). With the aim of providing a general understanding of the factors that dictate the strength of correlation between plant and animal occurrence and abundance, we developed probability of occurrence and count models for two species with very different life histories: bracken fern from northern Wisconsin, USA; and moose from northern British Columbia, Canada. For each species, we compared results of logistic regression occurrence models for low-density and high-density sample units as well as our global data set inclusive of the range of observed bracken or moose densities. We then used zero-inflated negative binomial (ZINB) and Poisson (ZIP) count models to assess whether environmental factors determining occurrence also were related to abundance in a simultaneous modeling process. Our working hypothesis was that if occurrence and abundance based on environmental conditions were functionally related we should observe: 1) correlation between predicted probability of occurrence and observed abundance; 2) similar environmental covariates and estimated coefficients for occurrence models developed separately for low-density, highdensity, and global data (full range of densities) sites; and 3) parallel coefficients and covariate inclusion for the occurrence and abundance components of zeroinflated count models.

\section{Methods}

\section{Bracken in northern Wisconsin, USA}

\section{Study area and field sampling}

Fieldwork on bracken was conducted in 1996 at the 3488 ha Spread Eagle Barrens Natural Area in eastern Florence Co., Wisconsin $\left(45^{\circ} 51^{\prime} \mathrm{N}, 88^{\circ} 11^{\prime} \mathrm{W}\right)$. Using 1:24 000 USGS topographic maps, we stratified the study area into a 6.25 -ha $(250 \times 250 \mathrm{~m})$ grid and randomly selected 6 upland grid sites for further study. We stratified the sample grid into $50 \times 50 \mathrm{~m}$ quadrats (25 in total) and randomly sampled 2 locations per quadrat resulting in an average nearest neighbour distance within each grid of $26.3 \mathrm{~m}$. At each location, $1-\mathrm{m}^{2}$ circular quadrats were used to estimate bracken occurrence (presence or absence) and abundance (frond density). Tree ( $\geq 5 \mathrm{~cm}$ diameter at breast height; dbh) and shrub ( $<5 \mathrm{~cm} \mathrm{dbh}$ and $\geq 1 \mathrm{~m}$ in height) density were tallied in belt transects centred over quadrats. Transects were $10 \mathrm{~m}$ in length and 2 and $1 \mathrm{~m}$ in width for trees and shrubs, respectively. Densities of trees and shrubs were standardized to a $100-\mathrm{m}^{2}$ (0.001 ha) scale. Canopy cover for coniferous and deciduous overstory was estimated using foliar intercept above 
10-m transects. At each sample location, slope (\%) and aspect (degrees) were estimated using a clinometer and compass, respectively. Using slope and aspect measurements, we estimated a slope-aspect (topoedaphic) index ranging from -1 (mesic) to +1 (xeric) following that of Nielsen and Haney (1998). An index of slope position was further estimated for each site based on the location of the plot within the landscape. This index ranged from 0 (broad plain, $>100 \mathrm{~m}$ wide) to 5 (valley bottom or kettle) and represented the likelihood of a growing season frost from cold air drainage, as bracken is sensitive to such events (Watt 1970, Nielsen 1997). Soil characteristics for each quadrat were estimated from a composite sample of four soil cores $(2 \times 15 \mathrm{~cm})$ located in the cardinal corners of quadrats. Samples were analyzed for available potassium, percent soil organic matter, and soil pH. Percent cover of bare soil, lichens, Pennsylvania sedge Carex pennsylvanica, and sweet fern Comptonia peregrina were further estimated in quadrats to assess potential disturbance or competitive explanations in the distribution and abundance of bracken (Vaughan and Ormerod 2003). In total, 296 of the 300 quadrats were used for modeling as they contained all the covariates of interest.

\section{Moose in central British Columbia, Canada}

\section{Study area and field sampling}

Moose surveys were conducted over an area of ca $13000-\mathrm{km}^{2}$ of high-density winter range near Prince George, British Columbia $\left(53^{\circ} 54^{\prime} \mathrm{N}, 122^{\circ} 41^{\prime} \mathrm{W}\right)$. Our survey sample units were forestry cutblocks. In 1996, there were an estimated 6500 cutblocks across the study area, most of which were logged after the mid-1960s. We randomly selected co-ordinate pairs $(n=434)$ within the boundaries of the 4 corners of the study area. The cutblock nearest a co-ordinate was considered a potential sampling unit. During the winters of 1996/1997 and 1997/1998 we surveyed 149 and 180 cutblocks, respectively. However, many of the cutblocks identified and surveyed during the 1996/1997 winter were revisited and surveyed the following year. For these analyses, we used counts from only one of the two years, giving preference to the $1997 / 1998$ survey data. Removing counts of moose for the same units across both years we surveyed 24 and 180 cutblocks during the 1996/1997 and 1997/1998 winters, respectively. Nearest neighbour distance between cutblock samples averaged $3.3 \mathrm{~km}$.

One or two crews (each consisting of two observers, a navigator, and the pilot) surveyed cutblocks from a helicopter between 9 and 19 December 1996, and between 9 December 1997 and 9 January 1998. We conducted the surveys flying $65-95 \mathrm{~km} \mathrm{~h}^{-1}, 30-50 \mathrm{~m}$ above the ground. For each cutblock, the survey time, presence of fresh or old tracks, and number, age class, and sex of all moose were recorded. Because we surveyed open areas with a contrasting background and employed closely spaced flight lines we are confident that we recorded the presence and correct number of moose; however, we did not perform multiple visits to estimate sighting bias (Tyre et al. 2003). At the majority of locations, snow depth was measured with a meter stick. For those cutblocks without a suitable landing area for the helicopter $(n=32)$, we used snow depth data for other blocks and a distance-weighted mean to estimate depth.

After completion of the surveys, we reviewed digital forest inventory data and recorded the area and elevation of the cutblock, all stand-tending activities, and date of logging. Stand-tending activities are a component of most silvicultural plans and are designed to stimulate conifer regrowth through the exclusion of other competing species. We classified stand-tending activities as no treatment, mechanical brushing, burning, herbicide application, and other (manual girdling, juvenile spacing, pruning, sheep grazing, fertilising).

\section{Modeling strategies}

\section{Occurrence models and relationships with observed abundance}

We randomly divided field data into training $(85 \%)$ and testing $(15 \%)$ groups for model development and validation, respectively (Fielding and Bell 1997). We used logistic regression (Stata, Anon. 2001) to model the occurrence of bracken or moose based on the presence or absence of the species (response variable) and selected environmental covariates (Menard 1995). Occurrence models for bracken and moose were developed from a suite of 13 and 10 environmental covariates, respectively (Table 1). We applied quadratic terms to those covariates where non-linear responses were expected and used deviation coding to represent categorical variables. Deviation coding differs from indicator coding in that the effect of each variable in the set is contrasted against an overall mean effect of the independent variable, not an arbitrary reference class (Menard 1995). We used variance inflation factors (VIF) to assess covariates for multicollinearity. We assumed that multcollinearity was influential when VIF $>10$ or the mean of all VIFs were considerably $>1$ (Chatterjee et al. 2000). Given that spatial autocorrelation was likely among sample locations (Lennon 2000) and potentially inflating our Type I error rate (Diniz-Filho et al. 2003), we calculated robust (sandwich) estimates of variance (White 1980) using the robust and cluster options in Stata (Anon. 2001, Long and Freese 2003). We clustered observations within grids for all bracken models, thereby assuming independence between grid (cluster) observations, but not necessarily for observations within a grid (cluster). This inflated our 
Table 1. Predictor variables used to estimate occurrence and abundance of bracken fern in northern Wisconsin and moose across central British Columbia.

\begin{tabular}{lll}
\hline Species & \multicolumn{1}{c}{ Variable } & \multicolumn{1}{c}{ Description } \\
\hline Bracken & k & Potassium \\
& $\mathrm{k} 2$ & $\begin{array}{l}\text { Potassium squared (quadratic) } \\
\text { \% soil organic matter } \\
\text { \% }\end{array}$ \\
& om soil organic matter squared \\
& (quadratic)
\end{tabular}

variances in the presence of positive spatial autocorrelation and assured appropriate inferences. Although moose samples were spatially dispersed, to be conservative we inflated variances around point estimates using robust/sandwich estimates of variance. In the moose case, however, we did not specify cluster, as the data were not organized into spatially distinct groupings.

Occurrence models were developed for three levels of density: 1) global dataset representing the full range of observed densities; 2) low-density sample units ( $\leq 5$ fronds $\mathrm{m}^{-2}$ or $\leq 2.5$ moose/cut-block); and 3 ) high-density sample units $\left(>5\right.$ fronds $\mathrm{m}^{-2}$ or $>2.5$ moose/cut-block). We assumed that if occurrence and abundance were functionally related across the two density levels, models should contain similar covariates with coefficients of similar sign and strength. Cut-off levels for low- and high-density sample units were determined by assessing median levels of density for presence sites, so as to provide similar sample sizes for low- and high-density models. At each density level, we used an information-theoretic approach to select the most parsimonious model. Sets of a priori biologically plausible candidate models were generated (Table 2 ) and evaluated using a small sample correction $\mathrm{AIC}_{\mathrm{c}}$ (Anderson et al. 2000). The best model of the suite of candidate models had the largest Akaike weight $\left(\mathrm{w}_{\mathrm{i}}\right)$. We used the $\mathrm{AIC}_{\mathrm{c}}$ selected "best" model for the global dataset to assess relationships between predicted occurrence and observed abundance. Where $\mathrm{AIC}_{\mathrm{c}}$ weights were similar, we used multi-model inference (MMI) for coefficients and unconditional standard errors (Anderson et al. 2000). Probability of occurrence for each observation was estimated and compared to observed abundance using a Somers' D statistic (ranging from -1 for complete discordance to 1 for complete concordance; Somers 1962, Newson 2001). We examined the occurrence-abundance relationship using two tests, 1) probability of occurrence against abundance-when-present (omitting absences) samples (Wright 1991); and 2) probability of occurrence against abundance with all samples (including absences). The former test represents the contribution to explaining abundance solely, while the latter includes the discrimination of absent locations (e.g. the logistic process). Somers' D tests were performed on both model training $\left(\mathrm{D}_{\text {train }}\right)$ and model testing $\left(\mathrm{D}_{\text {test }}\right)$ data. We used the receiver operating characteristics (ROC) and associated area under the curve estimates to evaluate the predictive accuracy of occurrence models (Metz 1978). ROC values ranging from 0.5 to 0.7 were considered to have low model accuracy, 0.7 to 0.9 good model accuracy, and $>0.9$ high model accuracy (Swets 1988, Manel et al. 2001). Both model training (within-sample) and model testing (out-of-sample) data were evaluated with ROC. Percent of deviance explained $\left(\mathrm{D}^{2}\right)$ was used to qualitatively assess the level of explanation in the data, while likelihood ratio $\chi^{2}$ tests were used to assess overall model significance.

\section{Zero-inflated count models}

We used zero-inflated negative binomial (ZINB) or Poisson (ZIP) count models (Anon. 2001) to quantify the effects of environment on abundance of bracken and moose. Although zero-inflated methods were likely given the large number of zero observations within the data (Fig. 1), we used a Vuong (V) test (Vuong 1989) to determine if ZINB or ZIP models were required. The zero-inflated count models assumed two latent groups: group A, an always-0 group (inflation group); and group $\sim$ A, a not always- 0 group. Individuals in group A have an outcome of 0 with a probability of 1 , while individuals in A might have a zero count, but there is a nonzero probability of being a positive count (Long and Freese 2003). We used $\mathrm{AIC}_{\mathrm{c}}$ to rank and select the most 
Table 2. A priori candidate models used for bracken fern and moose occurrence and abundance modeling. Model number (\#), name, structure, and total parameters $(\mathrm{K})$ including constant are provided.

\begin{tabular}{|c|c|c|c|}
\hline Model \# & Model name & Model structure & K \\
\hline \multicolumn{4}{|c|}{ a. Bracken model } \\
\hline 1 & Site model & sai + sai $2+$ slpp & 4 \\
\hline 2 & Ground layer model & lichen + bare + sweetfern + pensedge & 5 \\
\hline 3 & Soil model & $\mathrm{ph}+\mathrm{ph} 2+\mathrm{k}+\mathrm{k} 2+\mathrm{om}+\mathrm{om} 2$ & 7 \\
\hline 4 & Basic site/stem model & $\mathrm{k}+\mathrm{om}+\mathrm{sai}+\mathrm{slpp}+$ tree + shrub & 7 \\
\hline 5 & Site and stem model & $\mathrm{k}+\mathrm{k} 2+\mathrm{om}+\mathrm{om} 2+\mathrm{sai}+\mathrm{sai} 2+\mathrm{slpp}+$ tree + shrub & 10 \\
\hline 6 & Site and canopy model & $\mathrm{k}+\mathrm{k} 2+\mathrm{om}+\mathrm{om} 2+\mathrm{sai}+\mathrm{sai} 2+\mathrm{slpp}+\mathrm{conif}+\mathrm{decid}$ & 10 \\
\hline \multicolumn{4}{|c|}{ b. Moose model } \\
\hline 1 & Forage availability & area + snow + treatment + postlog + postlog 2 & 9 \\
\hline 2 & Silvicultural treatment & area + treatment & 6 \\
\hline 3 & Disturbance history & area + treatment + postlog + postlog 2 & 8 \\
\hline 4 & Time since cutting & area + postlog + postlog 2 & 4 \\
\hline 5 & Site location & area + elevation + snow + elev $\times$ snow & 5 \\
\hline
\end{tabular}

parsimonious of the set of candidate models. Nonoverlapping 95\% confidence intervals were compared between groups and by variable to determine whether the two processes differed. To assure appropriate confidence intervals and inferences in the presence of spatial autocorrelation we adjusted variances as described in the previous section. We used percent of deviance explained $\left(D^{2}\right)$ to quantify fit of the count models. Plots of predicted probability of each count against observed probabilities were used to visually assess model fit. We used out-of-sample model testing data to assess ZINB
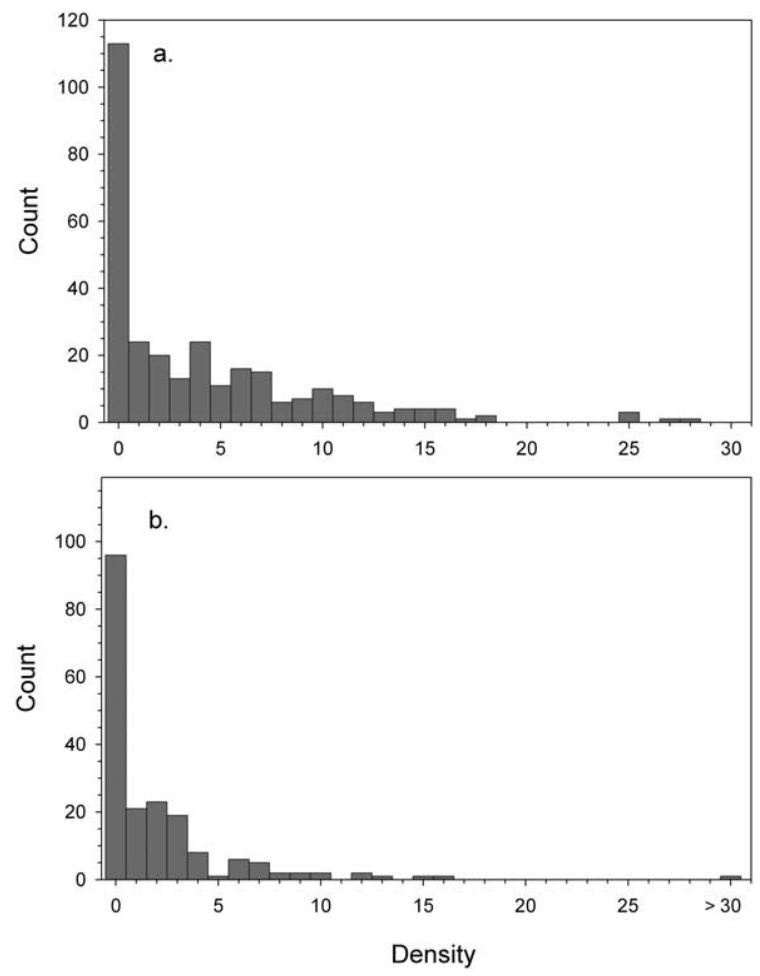

Fig. 1. Density of bracken fern fronds within $1-\mathrm{m}^{2}$ quadrats at Spread Eagle Barrens Natural Area in northern Wisconsin, USA (a.) and moose counts within cut-block survey units of central British Columbia, Canada, during winter (b.). and ZIP model predictive performance by comparing observed counts (model testing group) with predicted counts.

\section{Results}

\section{Species occurrence}

In total, 183 of $296(61.8 \%)$ quadrats contained bracken (Fig. 1). Of the six a priori $\mathrm{AIC}_{\mathrm{c}}$ models tested for bracken occurrence, the site and stem model had the greatest support (Table 3 ). The model was statistically significant $\left(\chi^{2}=134.4, \mathrm{p}<0.001, \mathrm{DF}=9\right)$, explained $40.4 \%$ of the deviance $\left(\mathrm{D}^{2}\right)$ and had good model accuracy for both model training $(\mathrm{ROC}=0.894)$ and model testing $(\mathrm{ROC}=0.792)$ data groups. Bracken distribution was related to available soil potassium, soil organic matter, and the slope-aspect index under Gaussian response curves with optimal occurrence at intermediate levels of resources (Table 4). Slope position was negatively related to bracken fern occurrence with kettles less likely and broad plains more likely to have bracken present. Finally, both tree and shrub densities were positively related to bracken occurrence (Table 4).

Predicted probability of occurrence from the $\mathrm{AIC}_{\mathrm{c}}$ selected model was poorly correlated with observed abundance-when-present $\quad\left(\mathrm{D}_{\text {train }}=-0.036 \pm\right.$ $0.051, \mathrm{p}=0.478 ; \mathrm{D}_{\text {test }}=-0.167 \pm 0.164, \mathrm{p}=0.308$ ), indicating little if any relationship between occurrence and observed frond densities $\geq 1$. We noted a significant relationship when all quadrats (including absences) were included $\quad\left(\mathrm{D}_{\text {train }}=0.358 \pm 0.033, \quad \mathrm{p}<0.001 ; \quad \mathrm{D}_{\text {test }}=\right.$ $0.240 \pm 0.097, \mathrm{p}=0.013)$ suggesting a large discrimination in probabilities at absent and present locations (Fig. 2).

Of the cut-blocks surveyed, 95 of $191 \quad(49.7 \%)$ contained moose (Fig. 1). For moose occurrence, $\mathrm{AIC}_{\mathrm{c}}$ suggested considerable model selection uncertainty when selecting from candidate models for all cut-blocks (Table 5). Percent deviance explained $\left(\mathrm{D}^{2}\right)$ ranged from 
Table 3. Candidate logistic regression models, number of parameters $(\mathrm{K}),-2 \log$ likelihood scores $(-2 \mathrm{LL})$, \% deviance explained $\left(\mathrm{D}^{2}\right), \mathrm{AIC}_{\mathrm{c}}$ scores, differences among $\mathrm{AIC}_{\mathrm{c}}$ scores $\left(\Delta_{\mathrm{i}}\right)$, and $\mathrm{AIC}_{\mathrm{c}}$ weights $\left(\mathrm{w}_{\mathrm{i}}\right)$ describing bracken fern occurrence in vegetation quadrats in northern Wisconsin.

\begin{tabular}{|c|c|c|c|c|c|c|c|}
\hline Model \#/density level & Model name & $\mathrm{K}$ & $-2 \mathrm{LL}$ & $\mathrm{D}^{2}$ & $\mathrm{AIC}_{\mathrm{c}}$ & $\Delta_{\mathrm{i}}$ & $\mathrm{w}_{\mathrm{i}}$ \\
\hline a. All quadrats & & Null & 332.9 & & & & \\
\hline 1 & Site model & 4 & 253 & 24.0 & 260.2 & 41.7 & $<0.001$ \\
\hline 2 & Ground layer model & 5 & 300 & 9.9 & 309.2 & 90.7 & $<0.001$ \\
\hline 3 & Soil model & 9 & 271 & 18.6 & 288.7 & 70.2 & $<0.001$ \\
\hline 4 & Basic site/stem model & 7 & 225.2 & 32.4 & 238.7 & 20.1 & $<0.001$ \\
\hline 5 & Site and stem model & 10 & 198.6 & 40.3 & 218.5 & 0.0 & 0.982 \\
\hline 6 & Site and canopy model & 10 & 206.6 & 37.9 & 226.5 & 8.0 & 0.018 \\
\hline b. Low-density & & Null & 232.1 & & & & \\
\hline 1 & Site model & 4 & 178.9 & 22.9 & 186.1 & 37.2 & $<0.001$ \\
\hline 2 & Ground layer model & 5 & 208.3 & 10.3 & 217.7 & 68.7 & $<0.001$ \\
\hline 3 & Soil model & 9 & 187.4 & 19.3 & 205.5 & 56.5 & $<0.001$ \\
\hline 4 & Basic site/stem model & 7 & 145.2 & 37.4 & 158.9 & 9.9 & 0.007 \\
\hline 5 & Site and stem model & 10 & 128.6 & 44.6 & 149.0 & 0.0 & 0.987 \\
\hline 6 & Site and canopy model & 10 & 138.7 & 40.2 & 159.1 & 10.1 & 0.006 \\
\hline c. High-density & & Null & 244.7 & & & & \\
\hline 1 & Site model & 4 & 179.5 & 26.6 & 186.7 & 19.1 & $<0.001$ \\
\hline 2 & Ground layer model & 5 & 219.6 & 10.3 & 228.9 & 61.3 & $<0.001$ \\
\hline 3 & Soil model & 9 & 188.5 & 23.0 & 206.6 & 39.0 & $<0.001$ \\
\hline 4 & Basic site/stem model & 7 & 168.4 & 31.2 & 182.1 & 14.4 & $<0.001$ \\
\hline 5 & Site and stem model & 10 & 147.3 & 39.8 & 167.6 & 0.0 & 0.537 \\
\hline 6 & Site and canopy model & 10 & 147.6 & 39.7 & 167.9 & 0.3 & 0.462 \\
\hline
\end{tabular}

3.5 to $15.4 \%$. Model accuracy was good for both training $(\mathrm{ROC}=0.765)$ and testing $(\mathrm{ROC}=0.782)$ data. Based on MMI estimates, strong relationships were evident for the post-logging and the quadratic of postlogging terms indicating that the number of years since logging was important and non-linear (Table 6). Occurrence of moose during winter was greatest for cut-blocks at ca $20 \mathrm{yr}$ in age. Predicted probability of occurrence from MMI marginally correlated with observed abundance-when-present cut-blocks $(\mathrm{D}=0.180 \pm 0.070, \mathrm{p}=$ $0.010)$, while a relationship with abundance $\left(\mathrm{D}_{\text {train }}=\right.$ $0.300 \pm 0.045, \mathrm{p}<0.001 ; \mathrm{D}_{\text {test }}=0.353 \pm 0.099, \mathrm{p}<$ 0.001 ) was evident when absent (zero) locations were included. Apparently, however, predicted probabilities of occurrence were more closely related to observed densities when moose numbers were $<7$ animals (Fig. 2). The relationship (abundance-when-present) between predicted probability of occurrence and moose abun- dance for cut-blocks with $<7$ animals was significant $(\mathrm{D}=0.160 \pm 0.074, \mathrm{p}=0.031)$.

\section{Density effects on occurrence models}

For bracken, occurrence models developed for low-density quadrats showed similar model selection (Table 3) and coefficient coverage (Table 4) with the global occurrence model described above. The site and stem model was significant $\left(\chi^{2}=103.5, \mathrm{p}<0.001\right.$, $\mathrm{DF}=9)$, explained $44.6 \%$ of the deviance $\left(\mathrm{D}^{2}\right)$, had high model accuracy for model training data $(\mathrm{ROC}=0.914)$, and good accuracy for model testing data $(\mathrm{ROC}=$ 0.842). In comparison, for the high-density models there was greater model selection uncertainty; the site and stem model was significant overall $\left(\chi^{2}=97.4, \mathrm{p}<0.001\right.$, $\mathrm{DF}=9)$, explained $39.8 \%$ of the deviance $\left(\mathrm{D}^{2}\right)$, and had

Table 4. Estimated coefficients and 95\% confidence intervals (CI) for logistic regression models contrasting presence of bracken fern at global, low- and high-density sites with absent locations. Confidence intervals ( $95 \%)$ were based on robust estimates of variance to account for possible autocorrelation within sample grids (clustering on within-grid observations).

\begin{tabular}{|c|c|c|c|c|c|c|}
\hline \multirow{2}{*}{$\begin{array}{l}\text { Variable } \\
\text { (code) }\end{array}$} & \multicolumn{2}{|c|}{ Global dataset } & \multicolumn{2}{|c|}{ Low-density } & \multicolumn{2}{|c|}{ High-density } \\
\hline & Coef. & $95 \% \mathrm{CI}$ & Coef. & $95 \% \mathrm{CI}$ & Coef. & $95 \% \mathrm{CI}$ \\
\hline $\mathrm{k}$ & 0.125 & $(0.071,0.179)$ & 0.094 & $(0.016,0.171)$ & 0.146 & $(0.096,0.197)$ \\
\hline $\mathrm{k} 2$ & -0.001 & $(-0.001,<-0.001)$ & -0.001 & $(-0.001,<0.001)$ & -0.001 & $(-0.001,<-0.001)$ \\
\hline om & 7.188 & $(2.832,11.545)$ & 8.123 & $(2.032,14.215)$ & 6.250 & $(2.777,9.723)$ \\
\hline om2 & -1.371 & $(-2.188,-0.554)$ & -1.580 & $(-2.717,-0.442)$ & -1.136 & $(-1.766,-0.505)$ \\
\hline sai & 0.594 & $(-1.596,2.784)$ & 0.988 & $(-0.980,2.957)$ & 0.104 & $(-2.385,2.593)$ \\
\hline sai2 & -3.130 & $(-6.320,-0.060)$ & -2.083 & $(-4.847,0.680)$ & -3.847 & $(-8.183,0.489)$ \\
\hline slpp & -0.934 & $(-1.287,-0.580)$ & -0.992 & $(-1.291,-0.693)$ & -0.917 & $(-1.402,-0.432)$ \\
\hline tree & 0.080 & $(0.031,0.129)$ & 0.114 & $(0.064,0.164)$ & 0.041 & $(-0.019,0.100)$ \\
\hline shrub & 0.003 & $(<0.001,0.006)$ & 0.004 & $(0.001,0.007)$ & 0.001 & $(-0.004,0.004)$ \\
\hline conif & - & - & - & - & - & - \\
\hline decid & - & - & - & - & - & - \\
\hline constant & -9.558 & $(-16.124,-2.991)$ & -10.759 & $(-19.873,-1.645)$ & -9.703 & $(-15.793,-3.612)$ \\
\hline
\end{tabular}



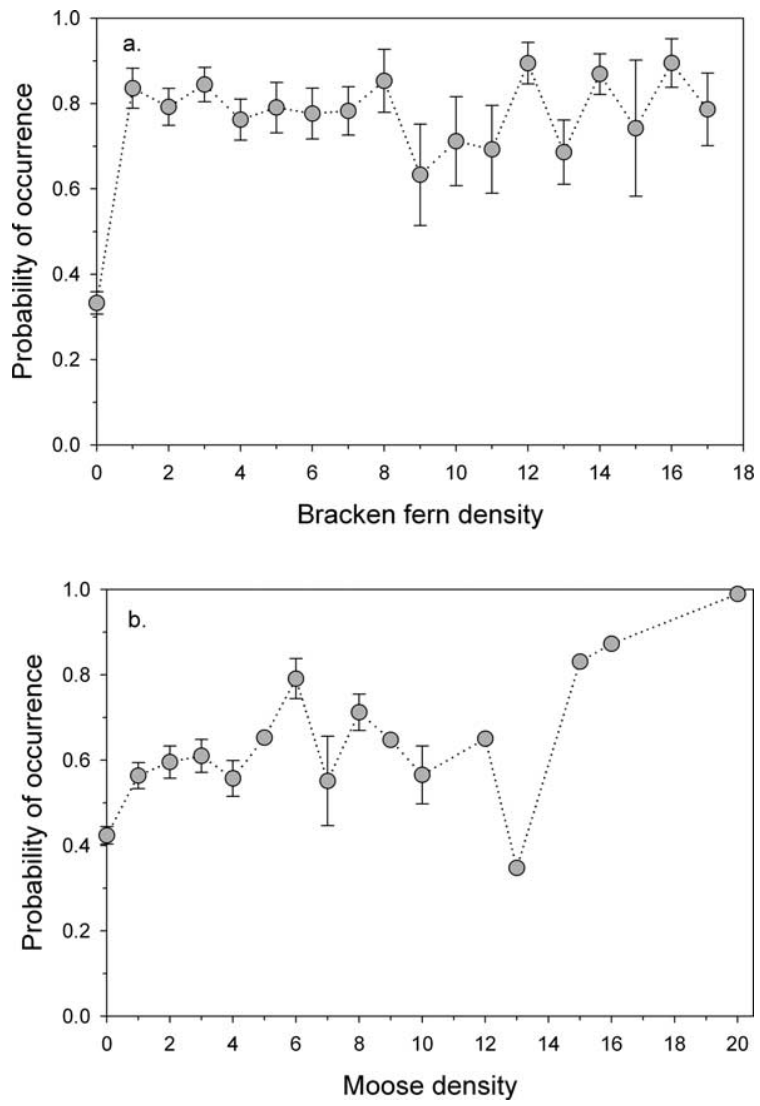

Fig. 2. Relationship among observed bracken fern frond density in $1-\mathrm{m}^{2}$ quadrats (a.) or moose counts in winter cutblocks (b.) and the mean $( \pm \mathrm{SE})$ estimated probability of occurrence from the $\mathrm{AIC}_{\mathrm{c}}$-selected logistic regression model.

good model accuracy for both model training $(\mathrm{ROC}=$ 0.891 ) and model testing $(\mathrm{ROC}=0.717)$ data groups. Coefficient coverage was similar across the low-, high- density, and global models suggesting that environmental conditions did not vary considerably across density levels.

For moose, occurrence models developed at lowdensity cut-blocks showed strong support for the time since cutting model, with $20.3 \%$ of the deviance explained $\left(D^{2}\right)$ and overall model significance $\left(\chi^{2}=14.94\right.$, $\mathrm{p}=0.002$, DF $=3$; Table 5). Coefficient coverage was similar to the model using global data (Table 6). ROC scores for both the model training $(\mathrm{ROC}=0.790)$ and model-testing $(\mathrm{ROC}=0.886)$ data suggested that the time since cutting model had good predictive capacity. At high-density cut-blocks there was model selection uncertainty between the forage availability and disturbance history models (Table 5). The two models had 17.0 and $16.2 \%$ of their deviance explained, respectively. Prediction success was again good for model training $(\mathrm{ROC}=0.795)$ and model testing $(\mathrm{ROC}=0.718)$ data. MMI adjusted confidence intervals for the low- and high-density models overlapped suggesting that density does not have a large effect on habitat-selection patterns of moose. Despite coefficient similarities, moose in highdensity cut-blocks demonstrated stronger selection for mechanical treatment, while typically avoiding cutblocks without treatment. In contrast, silvicultural treatment appeared to have much less influence for low-density sample units (Table 6).

\section{Zero-inflated count models}

For bracken fern, a ZINB model proved a better fit than a ZIP model (Fig. 3). The $\mathrm{AIC}_{\mathrm{c}}$ selected ZINB model indicated that processes influencing occurrence differed from those affecting abundance (Table 7). The site and canopy model was the most parsimonious describing bracken fern abundance (group $\sim$ A), given that group A

Table 5. Candidate logistic regression models, number of parameters $(\mathrm{K}),-2$ log likelihood scores $(-2 \mathrm{LL}), \%$ deviance explained $\left(\mathrm{D}^{2}\right), \mathrm{AIC}_{\mathrm{c}}$ scores, differences among $\mathrm{AIC}_{\mathrm{c}}$ scores $\left(\Delta_{\mathrm{i}}\right)$, and $\mathrm{AIC}_{\mathrm{c}}$ weights $\left(\mathrm{w}_{\mathrm{i}}\right)$ describing moose occurrence in forestry cut-blocks across central British Columbia.

\begin{tabular}{|c|c|c|c|c|c|c|}
\hline Model \#/density level & $\mathrm{K}$ & $-2 \mathrm{LL}$ & $\mathrm{D}^{2}$ & $\mathrm{AIC}_{\mathrm{c}}$ & $\Delta_{\mathrm{t}}$ & $\mathrm{w}_{\mathrm{i}}$ \\
\hline a. All cut-blocks & Null & 221.7 & & & & \\
\hline 1 Forage availability & 9 & 187.7 & 15.4 & 206.9 & 4.1 & 0.189 \\
\hline 2 Silvicultural treatment & 6 & 214 & 3.5 & 226.5 & 23.8 & $<0.001$ \\
\hline 3 Disturbance history & 8 & 188 & 15.2 & 205 & 2.2 & 0.487 \\
\hline 4 Time since cutting & 4 & 197.5 & 10.9 & 205.8 & 3 & 0.323 \\
\hline 5 Site location & 5 & 209.3 & 5.6 & 219.7 & 16.9 & $<0.001$ \\
\hline b. Low-density & Null & 142.9 & & & & \\
\hline 1 Forage availability & 9 & 109.3 & 23.5 & 129 & 8.8 & 0.032 \\
\hline 2 Silvicultural treatment & 6 & 132.8 & 7.1 & 145.5 & 25.3 & $<0.001$ \\
\hline 3 Disturbance history & 8 & 110 & 23 & 127.4 & 7.2 & 0.072 \\
\hline 4 Time since cutting & 4 & 114 & 20.3 & 122.4 & 2.2 & 0.896 \\
\hline 5 Site location & 5 & 133.8 & 6.4 & 144.4 & 24.2 & $<0.001$ \\
\hline c. High-density & Null & 164.2 & & & & \\
\hline 1 Forage availability & 9 & 136.3 & 17 & 155.9 & 3.3 & 0.307 \\
\hline 2 Silvicultural treatment & 6 & 159.3 & 3 & 172 & 19.5 & $<0.001$ \\
\hline 3 Disturbance history & 8 & 137.6 & 16.2 & 154.9 & 2.3 & 0.506 \\
\hline 4 Time since cutting & 4 & 148.6 & 9.5 & 156.9 & 4.3 & 0.182 \\
\hline 5 Site location & 5 & 153.7 & 6.4 & 164.2 & 11.6 & 0.005 \\
\hline
\end{tabular}


Table 6. Estimated coefficients and $95 \%$ confidence intervals for logistic regression models contrasting presence of moose in central British Columbia at global, low- and high-density winter cut-blocks relative to cut-blocks where moose were not sighted. Confidence intervals $(95 \%)$ were based on robust estimate of variance to account for possible autocorrelation among samples.

\begin{tabular}{|c|c|c|c|c|c|c|}
\hline \multirow{2}{*}{$\begin{array}{l}\text { Variable } \\
\text { (code) }\end{array}$} & \multicolumn{2}{|c|}{ Global dataset } & \multicolumn{2}{|c|}{ Low-density } & \multicolumn{2}{|c|}{ High-density } \\
\hline & Coef. & $95 \% \mathrm{CI}$ & Coef. & $95 \% \mathrm{CI}$ & Coef. & $95 \% \mathrm{CI}$ \\
\hline no treat & -0.041 & $(-0.795,0.713)$ & -0.036 & $(-0.274,0.202)$ & -0.864 & $(-2.289,0.560)$ \\
\hline mechanical & 0.902 & $(-0.582,2.385)$ & 0.124 & $(-0.334,0.583)$ & 1.334 & $(-0.213,2.881)$ \\
\hline burn & 0.008 & $(-0.578,0.594)$ & 0.02 & $(-0.129,0.168)$ & 0.259 & $(-0.578,1.095)$ \\
\hline herbicide & -0.336 & $(-1.026,0.354)$ & -0.053 & $(-0.271,0.165)$ & -0.138 & $(-0.851,0.575)$ \\
\hline other & -0.533 & $(-1.396,0.330)$ & -0.055 & $(-0.281,0.172)$ & -0.59 & $(-1.420,0.240)$ \\
\hline postlog & 0.438 & $(0.174,0.703)$ & 0.829 & $(0.381,1.277)$ & 0.369 & $(0.061,0.676)$ \\
\hline postlog2 & -0.011 & $(-0.018,-0.003)$ & -0.022 & $(-0.035,-0.009)$ & -0.007 & $(-0.015,0.001)$ \\
\hline snow & 0.001 & $(-0.003,0.005)$ & $<-0.001$ & $(-0.001,0.001)$ & 0.003 & $(-0.008,0.014)$ \\
\hline elevation & $<-0.001$ & $(<-0.001,0.001)$ & $<-0.001$ & $(<-0.001,0.001)$ & $<-0.001$ & $(<-0.001,0.001)$ \\
\hline snow $\times$ elev & $<-0.001$ & $(<-0.001,0.001)$ & $<0.001$ & $(<-0.001,0.001)$ & $<-0.001$ & $(<-0.001,0.001)$ \\
\hline area & 0.004 & $(-0.003,0.012)$ & 0.007 & $(<-0.001,0.014)$ & 0.003 & $(-0.001,0.008)$ \\
\hline constant & -3.903 & $(-6.254,-1.553)$ & -8.036 & $(-11.841,-4.232)$ & -4.49 & $(-7.308,-1.672)$ \\
\hline
\end{tabular}

was defined as the $\mathrm{AIC}_{\mathrm{c}}$ selected occurrence model (site and stem model; $\chi^{2}=36.0, \mathrm{p}<0.001, \mathrm{DF}=9$ ). For the abundance model (group $\sim$ A), deciduous and coniferous canopy cover and percent soil organic matter had the strongest influence on the density of bracken fern (Table 8). Although occurrence of bracken fern was more likely at high levels of conifer and deciduous canopy, density of fronds decreased with increasing canopy cover, further suggesting that processes influencing occurrence and abundance were dissimilar. Finally, coefficient coverage between group A and $\sim$ A was significantly different for slope position, having a strong influence on occurrence, but little to no impact on abundance.

Insufficient sample size prevented the fitting of ZINB models for moose, thus ZIP models were used. The sitelocation model was the most parsimonious of the set of candidate models tested (Table 7), was statistically significant $\left(\chi^{2}=225.9, \mathrm{p}<0.001, \mathrm{DF}=4\right)$, and had good visual concurrence between probability of observed and expected counts (Fig. 3). The ZIP model suggested that the probability of moose occurrence in cut-blocks was positively related to snow depth and that moose density was greater in large low-elevation cut-blocks (Table 8).

\section{Discussion}

Understanding patterns of species occurrence and abundance is a central theme of ecology. Recent advances have made statistical modelling of occurrence common (Guisan and Zimmerman 2000, Manly et al. 2002). Often, conservation biologists and wildlife managers have measures of occurrence, not abundance, yet are interested in population numbers and demographics. One approach suggested by Boyce and McDonald (1999) is to stratify an estimated population into habitat densities based on a probability of occurrence model.
The assumption is that probability of occurrence is positively related to abundance (Perkins et al. 2000, Moorcroft et al. 2002). When sampling frames are small, specifically the size that allows for only a single individual to occupy it, estimates of populations from occurrence models are simply the sum of probabilities (Manly et al. 2002). In some cases, however, the sampling frame is too large to facilitate population estimates from occurrence models without assuming an occurrence-abundance relationship. Understanding whether occurrence scales with abundance at scales typical of most studies (Pearce and Ferrier 2001) is therefore important. We found that probability of occurrence predicted observed abundance poorly for bracken, while evidence for a relationship was apparent for moose at densities below 7 animals. Additional comparisons of density levels and zero-inflated count models revealed that processes determining occurrence were not always those determining abundance. Measured environmental conditions, although predictive of occupancy, were generally poor predictors of plant and animal abundance across all ranges of density. Life history, socio-competitive factors, and site history were probably important factors moulding observed abundance, once occupancy was established.

Presence of bracken was largely explained by soil nutrients and canopy variables, occurring most frequently at intermediate levels of resource gradients. In contrast, predictions of abundance were only weakly related to these same environmental resources and in some cases contradicting one another. Ultimately, it appeared that unmeasured factors were largely shaping observed patterns of bracken abundance. Time since establishment of bracken, for instance, was probably a major determinant of frond abundance. Clones of bracken readily establish following disturbance (Conway 1952), with the size of clone relating to age (Oinonen 1967). In Finland, Oinonen (1967) correlated bracken clone establishment and size to historic disturbances 

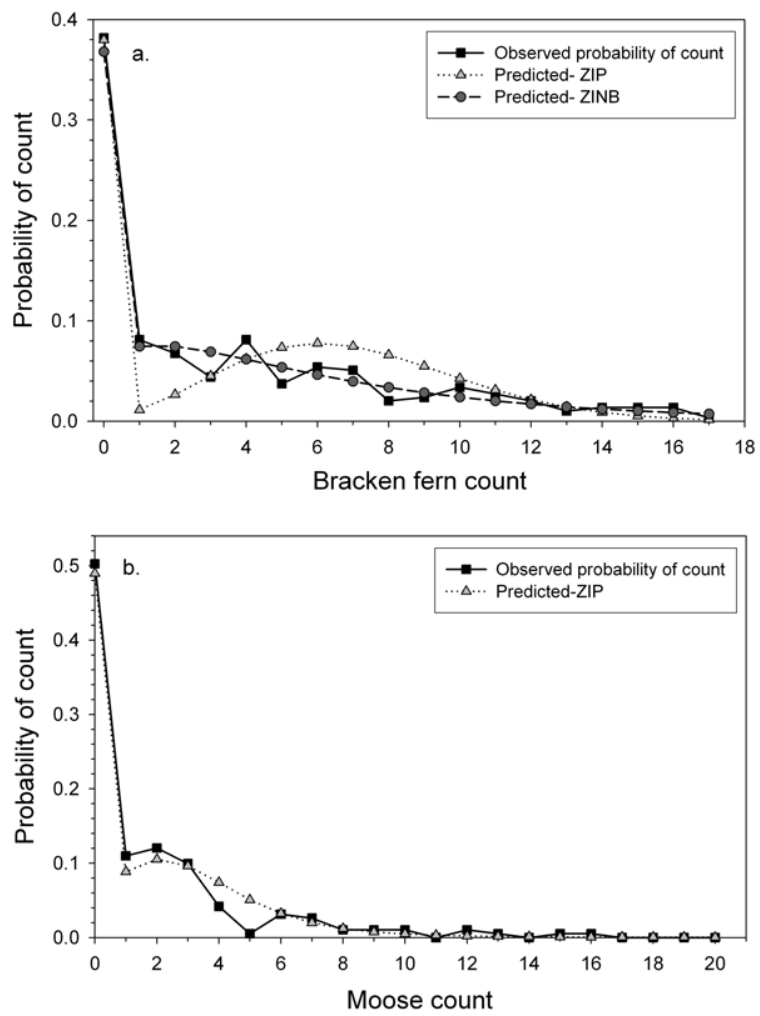

Fig. 3. Comparison of $\mathrm{AIC}_{\mathrm{c}}$ selected zero-inflated negative binomial (ZINB) and Poisson (ZIP) model predictions versus observed probabilities for (a.) bracken fern in $1-\mathrm{m}^{2}$ quadrats and (b.) moose in cut-blocks.

occurring $>350 \mathrm{yr}$ prior. As clones expand, patterns of abundance become apparent depending on the local phase of growth. Watt (1947) recognized four phases of growth characterized by the size and density of fronds within the clone. The invading front or pioneer phase was defined by few and relatively small fronds, while the building phase had progressively more and larger fronds. Bracken in the mature phase had large densities and sizes of fronds, while the final degenerate phase contained various mosaics of frond densities. Ultimately, the phase of growth for bracken is influenced by winter and spring frost, rainfall, and burning (Watt 1970). Based on the work of Watt $(1947,1970)$, it seems reasonable to assume life history, weather, and site history played a significant role in shaping bracken abundance, while more typical environmental resources, like those measured in this study (e.g. soil nutrients, light, etc.), largely explained occupancy. More powerful models of abundance will require the inclusion of covariates not directly associated with site productivity.

We developed highly predictive occurrence and abundance models for moose, which in contrast to bracken, factors dictating distribution were correlated with abundance. Although we noted some differences in the importance of environmental conditions, candidate models describing high- and low-density blocks had similar rankings. Time since cutting, disturbance history, and forage availability were all suitable models for predicting moose occurrence regardless of animal density. This result is not surprising considering that those three models contained similar variables that broadly represented the availability and production of forage. Silvicultural treatment and disturbance history, which were both constituents of the best models, are important factors dictating the regrowth of deciduous shrubs used by moose during winter as forage (Crete 1988, Eschholz et al. 1996, Rea and Gillingham 2001). Given that there are few territorial or social influences on the movements and aggregation of moose during this period, it is reasonable to expect a good correlation between forage availability and quality and moose distribution, up to some limiting density (Hobbs and Hanley 1990, Eklöv et al. 1999, Westerberg and Wennergren 2003).

Our data suggested that similar environmental factors influenced occurrence and abundance, but the relationship was not consistent across the range of moose densities observed. Although we surveyed few blocks

Table 7. Comparison of zero-inflated negative binomial (ZINB) candidate models for bracken fern and moose. The inflation model (logit) used for group A (zeros) was the $\mathrm{AIC}_{\mathrm{c}}$ selected global occurrence model, while candidate models presented represent models assessed for group ${ }^{\sim} \mathrm{A}$ (counts). Model number, name, number of parameters $(\mathrm{K}),-2 \log \operatorname{likelihood}(-2 \mathrm{LL}), \mathrm{AIC}_{\mathrm{c}}$ scores, differences among $\mathrm{AIC}_{\mathrm{c}}$ scores $\left(\Delta_{\mathrm{i}}\right)$, and $\mathrm{AIC}_{\mathrm{c}}$ weights $\left(\mathrm{w}_{\mathrm{i}}\right)$ are provided for model comparison. Deviance $\left(\mathrm{D}^{2}\right)$ is reported for the total model deviance (group A and $\sim$ A).

\begin{tabular}{|c|c|c|c|c|c|c|}
\hline Model \#/model name & $\mathrm{K}$ & $-2 \mathrm{LL}$ & $\mathrm{D}^{2}$ & $\mathrm{AIC}_{\mathrm{c}}$ & $\Delta_{\mathrm{i}}$ & $\mathrm{w}_{\mathrm{i}}$ \\
\hline a. Bracken model & Null & 1304.5 & & & & \\
\hline 1 Site model & 15 & 1092.6 & 16.2 & 1123.7 & 16.3 & $<0.001$ \\
\hline 2 Ground layer model & 16 & 1084.6 & 16.9 & 1117.9 & 10.5 & 0.005 \\
\hline 3 Soil model & 18 & 1094.8 & 16.1 & 1132.7 & 25.3 & $<0.001$ \\
\hline 4 Basic site/stem model & 18 & 1079.7 & 17.2 & 1117.6 & 10.2 & 0.006 \\
\hline 5 Site and stem model & 21 & 1075.2 & 17.6 & 1120.2 & 12.8 & 0.002 \\
\hline 6 Site and canopy model & 21 & 1062.4 & 18.6 & 1107.4 & 0.0 & 0.987 \\
\hline b. Moose model & Null & 811.6 & & & & \\
\hline 1 Forage availability & 18 & 567.0 & 30.1 & 607.9 & 24.6 & 0.001 \\
\hline 2 Silvicultural treatment & 12 & 610.7 & 24.7 & 636.8 & 53.5 & $<0.001$ \\
\hline 3 Disturbance history & 16 & 583.5 & 28.1 & 619.3 & 36.0 & $<0.001$ \\
\hline 4 Time since cutting & 8 & 596.6 & 26.5 & 613.5 & 30.2 & $<0.001$ \\
\hline 5 Site location & 10 & 572.9 & 29.4 & 594.4 & 11.1 & 0.999 \\
\hline
\end{tabular}


Table 8. $\mathrm{AIC}_{\mathrm{c}}$ selected coefficient and $95 \%$ confidence interval (CI) estimates for bracken fern zero-inflated negative binomial (ZINB) count model and zero-inflated Poisson (ZIP) count model for moose. Group A estimates relate to the process of being absent (sign is opposite for presence), while group $\sim$ A estimates relate to the abundance of bracken or moose.

\begin{tabular}{|c|c|c|c|c|}
\hline \multirow{2}{*}{$\begin{array}{l}\text { Species and } \\
\text { Variable name }\end{array}$} & \multicolumn{2}{|c|}{ Group A (zeros) } & \multicolumn{2}{|c|}{ Group A (counts) } \\
\hline & Coef. & $95 \% \mathrm{CI}$ & Coef. & $95 \% \mathrm{CI}$ \\
\hline \multicolumn{5}{|l|}{ a. Bracken } \\
\hline $\mathrm{k}$ & -0.302 & $(-0.512,-0.091)$ & -0.008 & $(-0.044,0.029)$ \\
\hline $\mathrm{k}^{2}$ & 0.003 & $(<0.001,0.005)$ & $<0.001$ & $(<-0.001,<0.001)$ \\
\hline om & -9.106 & $(-13.310,-4.902)$ & 1.380 & $(-0.471,3.230)$ \\
\hline $\mathrm{om}^{2}$ & 1.782 & $(0.934,2.630)$ & -0.254 & $(-0.578,0.071)$ \\
\hline sai & 0.043 & $(-3.433,3.519)$ & 0.429 & $(-0.467,1.325)$ \\
\hline $\mathrm{sai}^{2}$ & 6.640 & $(2.012,11.267)$ & -0.476 & $(-2.695,1.743)$ \\
\hline slpp & 1.300 & $(0.846,1.755)$ & -0.062 & $(-0.151,0.027)$ \\
\hline tree & -0.113 & $(-0.203,-0.023)$ & - & - \\
\hline shrub & -0.043 & $(-0.072,-0.014)$ & - & - \\
\hline conif & - & - & -0.011 & $(-0.016,-0.007)$ \\
\hline decid & - & - & -0.009 & $(-0.013,-0.004)$ \\
\hline constant & 14.346 & $(4.379,24.312)$ & 0.586 & $(-2.071,3.243)$ \\
\hline \multicolumn{5}{|l|}{ b. Moose } \\
\hline snow & -0.129 & $(-0.248,-0.009)$ & -0.005 & $(-0.061,0.051)$ \\
\hline elevation & -0.004 & $(-0.010,0.003)$ & -0.004 & $(-0.006,-0.001)$ \\
\hline snow $\times$ elev & $<0.001$ & $(<0.001,0.001)$ & $<0.001$ & $(<-0.001,0.001)$ \\
\hline area & -0.003 & $(-0.009,0.003)$ & 0.003 & $(0.002,0.003)$ \\
\hline constant & 2.990 & $(-1.805,7.775)$ & 3.461 & $(1.452,5.470)$ \\
\hline
\end{tabular}

with $>6$ moose, we found that those particular blocks did not always have attributes that corresponded with a high probability of moose occurrence. The discrepancy might be a function of variability in counts inherent to small sample sizes or environmental conditions.

Moose and bracken vary considerably in life history, scale of measurement and occurrence, and strength of response to environmental features. Given these differences, our case studies exemplify the potential range of influences on the outcome and success of occurrence and abundance models. Our results also suggest that in contrast to extensive and exploratory model fitting exercises (Pearce and Ferrier 2001), researchers wishing to develop abundance-environment relationships should review the life history of their subject species carefully relative to the availability and scale of predictor data. We present several general points drawn from our data and other studies that might guide researchers when considering the utility of count models or the strength of correlation between occurrence and abundance:

1) As resources become more limiting and patchy, especially for a habitat specialist, the strength of relationship between occurrence and abundance should increase. A relatively homogenous distribution of resources of a near uniform quality may reveal presenceabsence, but will likely prove difficult for modelling plant and animal abundance. If socio-behavioural factors are not influential and resources are freely available and of equal quality, then there is no mechanism for animals or plants to aggregate in patches. However, such responses can be confounded by population density and the scale of resource distribution (Hobbs and Hanley 1990, Edenius et al. 2002).
2) Strength of correlation between occurrence and abundance may ultimately depend on plant or animal density (Fretwell and Lucas 1970). After controlling for mechanisms that favour or dictate aggregation, we should observe little if any relationship between occurrence and abundance at low densities. Given equal access to all patches, animals or plants should distribute themselves to avoid competition for resources. As density increases, organisms will aggregate within good patches tolerating intraspecific competition until resource acquisition drops below resources available in neighbouring lower quality patches. At high densities, intraspecific competition will force animals into progressively inferior habitats (Van Horne 1983, Rangeley and Kramer 1998).

3) We should expect temporal variation in the relationship between occurrence and abundance. Interor intra-specific interactions such as reproduction in animals or dispersal in plants may relate only weakly to environmental conditions, but could be dominant factors determining distribution and abundance during certain times (Bowyer et al. 1999). For mobile species, distribution relative to resource type and amount of use may differ according to season leading to temporal variation in occurrence-abundance relationships (Mysterud et al. 2001).

4) Behavioural or social constraints on distribution, such as territoriality in animals or intra-specific allelopathy in plants, might result in good presence-absence, but poor abundance predictions (Ervin and Wetzel 2003, Focardi et al. 2003). If territory size varies according to availability or quality of resources then we may observe a relationship between occurrence and abundance at some scales (McLoughlin et al. 2000, Ochiai and Susaki 2002). 
Alternatively, species that hold areas of a size unrelated to environmental features would be poor candidates for abundance models.

\section{Conclusions}

Environmental factors influencing abundance may differ from those limiting distribution. The majority of explanation in our count models was in the description of absent locations. However, given that the majority of sites measured were absent locations (i.e. habitat poor), common in conservation studies (i.e. rare or endangered species), the dominance of explanation in occurrences likely reflects a real ecological process. Regardless, we did find that moose abundance at low- to mid-densities was related to predicted probability of occurrence. This suggests that occurrence-abundance relationships might be valid for some species and density levels. Alternatively, however, bracken abundance did not vary with measured environmental factors, instead relating to life history (phases of growth), weather (frost and rainfall), and site history. Extrapolation of indices of abundance from our occurrence models of bracken would be imprudent. Previous work has also warned of misuse of habitat models derived from presence data alone (Fagen 1988). Few would argue that habitat quality models and maps would be best described by direct abundance relationships. However, demographic performances for many species have been found to decrease as density of animals in habitats increase (Van Horne 1983, Breininger et al. 1998). In general, occurrence models enlighten management, but with few exceptions density models, followed by demographic models provide progressively more information, better our understanding of processes, and ultimately better management and conservation. We suggest caution when inferring habitat quality from occurrence models or extrapolating abundance from predicted probability of occurrence. Under certain scale, life history, or environmental conditions, these relationships may hold, but should not be assumed.

Acknowledgements - We thank Cameron Aldridge for suggestions during analysis and further providing a review of the manuscript. Financial support for the first author was in part provided by the FS Chia Ph.D. scholarship. Natural Science and Engineering Research Council (NSERC) of Canada provided additional support to the authors. Fieldwork in Wisconsin, administered through Alan Haney, was supported through funds from the Dept of Defense Legacy Project, Sand County Foundation, and MacIntire-Stennis grant number WIS04325. We thank Sean Barry, Andra Bismanis, John Metcalfe, Chris Ritchie, Jocelyn Salton, Glen Watts, Doug Wilson, Kathi Zimmerman and Ted Zimmerman for assisting with moose surveys and our pilots Dean Scarrow, Lee Sexsmith, and Greg Altoft. Jason Hart provided GIS support for the moose surveys and Colin Caroll and Kathi Zimmerman assisted with data preparation and processing. Funding for moose surveys was provided by the British Columbia Ministry of
Environment, Lands and Parks and Forest Renewal British Columbia.

\section{References}

Anderson, D. R., Burnham, K. P. and Thompson, W. L. 2000. Null hypothesis testing: problems, prevalence, and an alternative. - J. Wildl. Manage. 64: 912-923.

Anon. 2001. Stata version 7.0. - Stata Press.

Austin, M. P., Nicholls, A. O. and Margules, C. R. 1990. Determining the realized qualitative niche: environmental niches of five Eucalyptus species. - Ecol. Monogr. 60: 161177.

Barry, S. C. and Welsh, A. H. 2002. Generalized additive modelling and zero inflated count data. - Ecol. Modell. 157: $179-188$

Bowyer, R. T. et al. 1999. Birth-site selection by Alaskan moose: maternal strategies for coping with a risky environment. - J. Mammal. 80: 1070-1083.

Boyce, M. S. and McDonald, L. L. 1999. Relating populations to habitats using resource selection functions. - Trends Ecol. Evol. 14: 268-272.

Boyce, M. S. and Waller, J. 2003. Grizzly bears for the bitterroot: predicting potential abundance and distribution. - Wildl. Soc. Bull. 31: 670-683.

Boyce, M. S. et al. 2001. Negative binomial models for abundance estimation of multiple closed populations. - J. Wildl. Manage. 65: 498-509.

Breininger, D. R. et al. 1998. Linking habitat suitability to demographic success in Florida scrub-jays. - Wildl. Soc. Bull. 26: 118-128.

Chatterjee, S., Hadi, A. S. and Price, B. 2000. Regression analysis by example. - Wiley.

Conway, E. 1952. Bracken - the problem plant, a review of recent conclusions about its spread and dominance. - Scot. Agricult. 31: 181-184.

Crete, M. 1988. Forestry practices in Quebec and Ontario in relation to moose population dynamics. - For. Chron. 64: $246-250$

Diniz-Filho, F. et al. 2003. Spatial autocorrelation and red herrings in geographical ecology. - Global Ecol. Biogeogr. 12: $53-64$

Edenius, L., Ericsson, G. and Naslund, P. 2002. Selectivity by moose vs the spatial distribution of aspen: a natural experiment. - Ecography 25: 289-294.

Eklöv, A. G. et al. 1999. Influence of water quality, habitat and species richness on brown trout populations. - J. Fish Biol. 54: $33-43$.

Ervin, G. N. and Wetzel, R. G. 2003. An ecological perspective of allelochemical interference in land-water interface communities. - Plant Soil 256: 13-28.

Eschholz, W. E. et al. 1996. Winter use of glyphosate-treated clearcuts by moose in Maine. - J. Wildl. Manage. 60: 764769.

Fagen, R. 1988. Population effects of habitat change: a quantitative assessment. - J. Wildl. Manage. 52: 41-46.

Fielding, A. H. and Bell, J. F. 1997. A review of methods for the assessment of prediction error in conservation presence/ absence models. - Environ. Conserv. 24: 38-49.

Focardi, S. et al. 2003. Sexual segregation in ungulates: individual behaviour and the missing link. - Popul. Ecol. 45: 83-95.

Fretwell, S. D. and Lucas, H. L. 1970. On territorial behaviour and other factors influencing habitat distribution in birds. I. Theoretical development. - Acta Biotheor. 19: 16-36.

Gaston, K. J. and Lawton, J. H. 1990. Effects of scale and habitat on the relationship between regional distribution and local abundance. - Oikos 58: 329-335. 
Guisan, A. and Zimmermann, N. E. 2000. Predictive habitat distribution models in ecology. - Ecol. Modell. 135: 147186.

Guisan, A., Theurillat, J. P. and Kienast, F. 1998. Predicting the potential distribution of plant species in an alpine environment. - J. Veg. Sci. 9: 65-74.

He, F. and Gaston, K. J. 2000. Estimating species abundance from occurrence. - Am. Nat. 156: 553-559.

He, F., Gaston, K. J. and Wu, J. 2002. On species occupancyabundance models. - Ecoscience 9: 119-126.

Hobbs, N. T. and Hanley, T. A. 1990. Habitat evaluation: do use/availability data reflect carrying capacity? - J. Wildl. Manage. 54: 515-522.

Johnson, C. J., Seip, D. R. and Boyce, M. S. 2004. A quantitative approach to conservation planning: using resource selection functions to map the distribution of mountain caribou at multiple spatial scales. - J. Appl. Ecol. 41: 238-251.

Lennon, L. L. 2000. Red-shifts and red herrings in geographical ecology. - Ecography 23: 101-113.

Long, J. S. and Freese, J. 2003. Regression models for categorical dependent variables using stata, revised ed. - Stata Press.

Manel, S., Williams, H. C. and Ormerod, S. J. 2001. Evaluating presence-absence models in ecology: the need to account for prevalence. - J. Appl. Ecol. 38: 921-931.

Manly, B. F. J. et al. 2002. Resource selection by animals: statistical design and analysis for field studies. - Kluwer.

McCullagh, P. and Nelder, J. 1989. Generalized linear models. - Chapman and Hall.

McDonald, T. L. and McDonald, L. L. 2002. A new ecological risk assessment procedure using resource selection models and geographic information systems. - Wildl. Soc. Bull. 30: 1015-1021.

McLoughlin, P. D., Ferguson, S. H. and Messier, F. 2000. Intraspecific variation in home range overlap with habitat quality: a comparison among brown bear populations. - Evol. Ecol. 14: 39-60.

Menard, S. 1995. Applied logistic regression. - Sage Univ. Paper Series on Quantitative Applications in the Social Sciences, Series no. 07-106.

Metz, C. E. 1978. Basic principles of ROC analysis. - Semin. Nucl. Med. 8: 283-298.

Mladenoff, D. J. et al. 1995. A regional landscape analysis and prediction of favourable gray wolf habitat in the northern Great Lakes region. - Conserv. Biol. 9: 279-294.

Moorcroft, D. et al. 2002. The selection of stubble fields by wintering granivorous birds reflects vegetation cover and food abundance. - J. Appl. Ecol. 39: 535-547.

Mysterud, A., Perez-Barberia, F. J. and Gordon, I. J. 2001. The effect of season, sex and feeding style on home range area versus body mass scaling in temperate ruminants. - Oecologia 127: 30-39.

Newson, R. 2001. Parameters behind "non-parametric" statistics: Kendall's ta, Somers' D and median differences. - Stata J. 1: 1-20.

Nielsen, S. E. 1997. The influence of topoedaphic factors, canopy, and bracken fern on distributional patterns of plant species at Spread Eagle Barrens. - MS thesis, Univ. of Wisconsin-Stevens Point.

Nielsen, S. E. and Haney, A. 1998. Gradient responses for understory species in a bracken grassland and northern dry forest ecosystem of northeast Wisconsin. - T. Wisc. Acad. Sci. 86: 149-166.

Ochiai, K. and Susaki, K. 2002. Effects of territoriality on population density in the Japanese serow (Capricornis crispus). - J. Mammal. 83: 964-972.

Oinonen, E. 1967. The correlation between the size of Finnish bracken (Pteridium aquilinum (L.) Kuhn) clones and certain periods of site history. - Acta For. Fenn. 83: 1-51.

Pearce, J. and Ferrier, S. 2001. The practical value of modelling relative abundance of species for regional conservation planning: a case study. - Biol. Conserv. 98: 33-43.

Perkins, A. J. et al. 2000. Habitat characteristics affecting use of lowland agricultural grassland by birds in winter. - Biol. Conserv. 95: 279-294.

Rangeley, R. W. and Kramer, D. L. 1998. Density-dependent antipredator tactics and habitat selection in juvenile pollock. - Ecology 79: 943-952.

Rea, R. V. and Gillingham, M. P. 2001. The impact of the timing of brush management on the nutritional value of woody browse for moose Alces alces. - J. Appl. Ecol. 38: $710-719$.

Somers, R. H. 1962. A new asymmetric measure of association for ordinal variables. - Am. Soc. Rev. 27: 799-811.

Swets, J. A. 1988. Measuring the accuracy of diagnostic systems. - Science 240: 1285-1293.

Tyre, A. J. et al. 2003. Improving precision and reducing bias in biological surveys: estimating false-negative error rates. - Ecol. Appl. 13: 1790-1801.

Van Horne, B. 1983. Density as a misleading indicator of habitat quality. - J. Wildl. Manage. 47: 893-901.

Vaughan, I. P. and Ormerod, S. J. 2003. Improving the quality of distribution models for conservation by addressing shortcomings in the field collection of training. - Conserv. Biol. 17: $1601-1611$.

Vuong, Q. 1989. Likelihood ratio tests for model selection and non-nested hypotheses. - Econometrica 57: 307-334.

Watt, A. S. 1947. Contributions to the ecology of bracken (Pteridium aquilinum). IV. The structure of the community. - New Phytol. 46: 97-121.

Watt, A. S. 1970. Contributions to the ecology of bracken (Pteridium aquilinum). VII. Bracken and litter. The cycle of change. - New Phytol. 69: 431-449.

Welsh, A. H. et al. 1996. Modelling the abundance of rare species: statistical models for counts with extra zeros. - Ecol. Modell. 88: 297-308.

Westerberg, L. and Wennergren, U. 2003. Predicting the spatial distribution of a population in a heterogeneous landscape. - Ecol. Modell. 166: 53-65.

White, H. 1980. A heteroskedasticity-consistent covariance matrix estimator and a direct test for heteroskedasticity. - Econometrica 48: 817-830.

Wright, D. H. 1991. Correlations between incidence and abundance are expected by chance. - J. Biogeogr. 18: 463466. 